\title{
STUDIES ON THE DIFFERENCES IN ACTIVITY OF LUNG AND BRAIN THROMBOPLASTIN
}

\author{
By HARVEY J. WEISS, JAMES W. EICHELBERGER, JR. AND WILLIAM H. CROSBY \\ (From the Department of Hematology, Walter Reed Army Institute of Research, \\ Washington, D. C.)
}

(Submitted for publication July 25, 1960 ; accepted September 30, 1960)

Recent reports have suggested that thromboplastin $(\mathrm{Tpl})$ prepared from lung may reflect more accurately than does brain $\mathrm{T} p$ l the changes produced in the prothrombin complex by coumarin derivatives $(1,2)$. As evidence for this, it has been observed that as factor VII concentration decreases in the plasma of Dicumarol ${ }^{1}$-treated patients, the prothrombin time obtained with lung $\mathrm{T} p 1$ becomes disproportionately longer than that obtained with brain $\mathrm{Tpl}(1)$. The inference from this observation has been that brain $\mathrm{T} p \mathrm{pl}$ contains a factor VII-like activity, not possessed by lung Tpl. This activity would mask a lowered plasma concentration of factor VII and would result in spuriously short prothrombin times. Verstraete, Clark and Wright $(1,2)$ concluded that brain thromboplastins possess, although to a lesser degree, the disadvantage previously observed for Russell's viper venom $(3,4)$. The latter, by virtue of its intrinsic convertin-like activity, is insensitive to changes in factor VII concentration and is, therefore, no longer used in following anticoagulated patients.

Other observations, however, suggest that brain Tpl does not contain more factor VII activity than does lung and may, in fact, contain less. Mann and Hurn (5) have noted that contamination of the $\mathrm{T} p 1$ with small quantities of blood may result in marked enhancement of activity when tested on the plasma of patients receiving coumarin derivatives. If the factor VII-like activity of tissue $\mathrm{Tpl}$ was due to contamination by blood and not to intrinsic properties of $\mathrm{Tpl}$ itself, one would expect brain $\mathrm{T} p 1$ to show less such activity than lung $\mathrm{Tpl}$, inasmuch as lung preparations are more heavily contaminated by blood during their preparation. In addition, Verstraete and associates (1) found that when $\mathrm{T}$ pl solutions were adsorbed with $\mathrm{BaSO}_{4}$, lung $\mathrm{T}$ pl showed a pronounced decrease

\footnotetext{
1 Bishydroxycoumarin.
}

in activity when tested on the plasma of patients receiving Dicumarol, whereas brain $\mathrm{T}$ pl showed virtually no change.

An alternative explanation for the longer prothrombin times obtained with lung $\mathrm{Tpl}$ is suggested by the observations of Conley, Morse and Stewart (6). They showed that, if plasma was diluted with saline, the prothrombin times obtained with lung $\mathrm{T}$ pl became shorter than those obtained with the corresponding dilutions in $\mathrm{Ba}$ $\mathrm{SO}_{4}$-adsorbed plasma. This would suggest the presence in plasma of an inhibitor of lung Tpl.

The purpose of the present investigation was to study further the differences in activity of lung and brain Tpl.

\section{MATERIALS AND METHODS}

Collection of plasma. Nine parts of blood were mixed with one part of $0.1 \mathrm{M}$ sodium oxalate and the plasma separated after centrifuging at $3,000 \mathrm{rpm}$ for 10 minutes. Human plasma was used for all experiments. Normal plasmas were pooled by mixing equal parts from 5 donors.

$\mathrm{BaSO}_{4}$-adsorbed plasma. Plasma was incubated with $\mathrm{BaSO}_{\star}\left(100 \mathrm{mg}\right.$ per $\mathrm{ml}$ of plasma) at $37^{\circ} \mathrm{C}$ for $10 \mathrm{~min}$ utes and then removed after centrifuging.

Commercial thromboplastins. Alban Permaplastin (AP) was used as the source of rabbit brain extract Tpl, and Difco Aplastin (DA) as the source of rabbit lung Tpl. The latter, a dry material, was reconstituted each day by extracting $100 \mathrm{mg}$ of the powder with $4 \mathrm{ml}$ of saline at $50^{\circ} \mathrm{C}$ for 10 minutes. The extracts were not frozen, as this resulted in considerable loss of activity.

Prepared thromboplastins. Brain and lung Tpl's were prepared from normal rabbits and from Dicumarol-poisoned rabbits. Brain Tpl's were prepared by acetone dehydration (7) and were stored in air-evacuated glass ampuls. Aliquots were reconstituted on the day of use by extracting $100 \mathrm{mg}$ with $4 \mathrm{ml}$ of normal saline at $50^{\circ} \mathrm{C}$ for 10 minutes. Lung $\mathrm{Tpl}$ was prepared as described by Johnson and Seegers (8). The first 24-hour saline extract of the ground lung was discarded. The second 48-hour extract was used as the source of thromboplastin. Rabbits that received Dicumarol were given 
$5 \mathrm{mg}$ per $\mathrm{kg}$ of body weight each day for 4 days. When sacrificed, their prothrombin times (Permaplastin) were 2 minutes or longer.

Plasma prothrombin conversion inhibitor. To $50 \mathrm{ml}$ of $\mathrm{BaSO}_{4}$-adsorbed plasma was added an equal volume of saturated ammonium sulfate solution. After standing at $4^{\circ} \mathrm{C}$ for 10 hours, the material was centrifuged and the supernatant was removed. Saturated ammonium sulfate was then added to bring the final concentration to 80 per cent saturation. The precipitate which formed during 4 hours at $4^{\circ} \mathrm{C}$ was removed by filtration, dissolved in $5 \mathrm{ml}$ of water and dialyzed until free of the sulfate.

"Albumin-free" plasma fraction. Equal volumes of $\mathrm{BaSO}_{4}$-adsorbed plasma and saturated ammonium sulfate were mixed and allowed to stand 3 hours at $4^{\circ} \mathrm{C}$. After centrifuging, the precipitate was washed twice with cold 50 per cent ammonium sulfate. It was dissolved in saline (one-half the original plasma volume) and dialyzed against normal saline until free of the sulfate.

Plasma eluate. Twenty $\mathrm{ml}$ of plasma was incubated with $\mathrm{BaSO}_{4}$ as described. The $\mathrm{BaSO}_{4}$ was washed with cold saline and eluted with $2 \mathrm{ml}$ of $0.2 \mathrm{M}$ sodium citrate.

Serum eluate. Blood was allowed to clot and after 6 hours at $37^{\circ} \mathrm{C}$ the serum was removed by centrifugation. This was adsorbed with $\mathrm{BaSO}_{4}$ and citrate elution was carried out as for plasma.

Purified prothrombin. This preparation, containing Stuart factor but essentially free of factor VII activity, was kindly supplied by Dr. Sandor Shapiro of the National Institutes of Health.

One-stage prothrombin time (Quick). Equal parts of $\mathrm{Tpl}$ extract and $0.025 \mathrm{M} \mathrm{CaCl}_{2}$ were mixed together and $0.2 \mathrm{ml}$ of this mixture was added to $0.1 \mathrm{ml}$ of plasma.

\section{RESULTS}

1. Differences in activity between brain and lung $T p l$. Prothrombin times were determined using normal plasma diluted with saline and with $\mathrm{BaSO}_{4}$-adsorbed plasma (Figure 1). At higher dilutions with $\mathrm{BaSO}_{4}$ plasma, the lung $\mathrm{Tpl}$ gave increasingly longer prothrombin times than did brain $\mathrm{Tpl}$, resulting in a wide divergence of the curves. When saline was used as a diluent, the difference between the two Tpl's was considerably less and the curves obtained were almost parallel. Moreover, with brain $\mathrm{Tpl}$ the dilution of plasma with saline resulted in considerably longer prothrombin times than did comparable dilution with $\mathrm{BaSO}_{4}$-adsorbed plasma. When lung $\mathrm{Tpl}$ was used the curves obtained with both diluents were similar, and at high dilutions the values obtained with saline were even shorter than those with adsorbed plasma. These findings essentially confirm the observations of Conley and

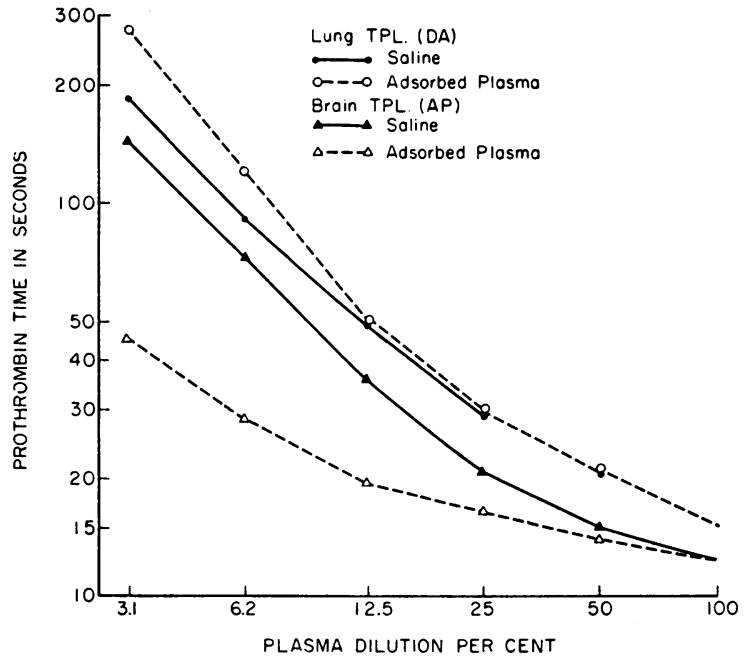

Fig. 1. The efFect of the diluent on the PROThromBIN TIMES OBTAINED WITH BRAIN (AP) AND LUNG (DA) TPL. Pooled, normal plasma was diluted with normal saline and with $\mathrm{BaSO}_{4}$-adsorbed plasma.

associates (6) and Verstraete and co-workers (1), and strongly suggest the presence in $\mathrm{BaSO}_{4}$-adsorbed plasma of an inhibitor of lung $\mathrm{Tpl}$ that becomes more effective at increasing dilutions of plasma.

Further evidence for the presence of an inhibitor was obtained by diluting plasma with "albuminfree" plasma fraction. The curves obtained with

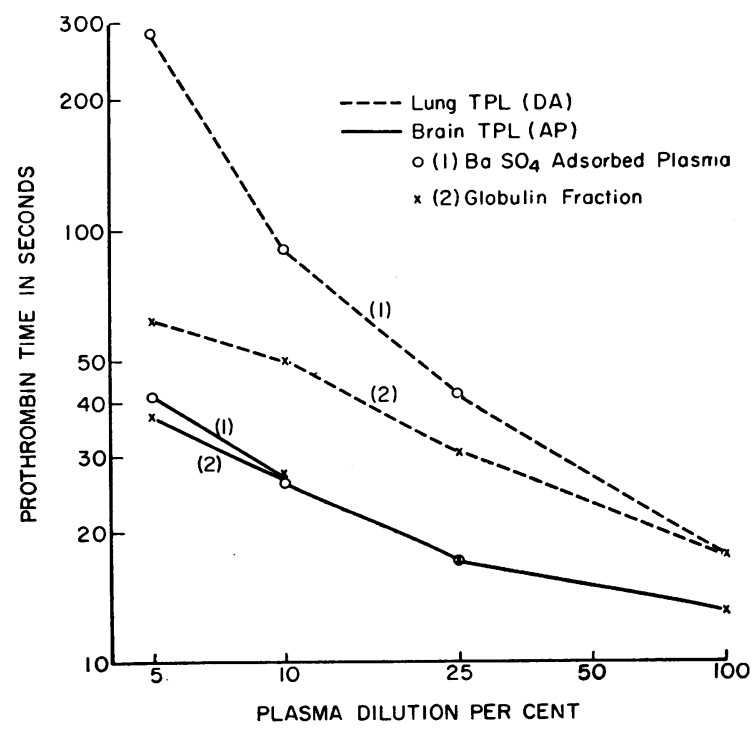

Fig. 2. Prothrombin tIMES OF POOLED, NORMAL PLASMA DILUTED IN 1) $\mathrm{BASO}_{4}$-AdSORBED PLASMA, 2) “ALBUMIN-FREE" PLASMA FRACTION PREPARED FROM BASO4-ADSORBED PLASMA. 
the two Tpl's were compared with those using the ordinary adsorbed plasma as diluent (Figure 2). When brain $\mathrm{T} p \mathrm{pl}$ was used there was virtually no difference between the two diluents. With lung Tpl, however, the curve obtained with "albuminfree" plasma was much flatter and was now parallel to the curve obtained with brain Tpl.

2. Evidence that brain thromboplastin does not possess a greater factor VII-like activity than lung. It has been observed that $\mathrm{Tpl}$ obtained from the tissues of Dicumarol-poisoned animals is less active with the plasma of coumarin-treated patients than is Tpl from normal animals (9-12). According to Mann and Hurn (5), this difference reflects the contamination of tissue $\mathrm{Tpl}$ with blood. If the blood trapped in the tissues has been depleted of coagulation factors, the $\mathrm{Tpl}$ extracted from these tissues would be correspondingly less active. If brain $\mathrm{T} p l$ contains more factor VII activity than lung, then Dicumarol poisoning would cause a greater change in the activity of brain $\mathrm{Tpl}$. To test this, plasma was diluted with $\mathrm{BaSO}_{4}$-adsorbed plasma and tested with brain and lung $\mathrm{Tpl}$ obtained from normal and Dicumarol-treated rabbits (Figure 3 ). The results show that pretreating animals with Dicumarol had a greater effect in decreasing the activity of lung $\mathrm{Tpl}$, suggesting that

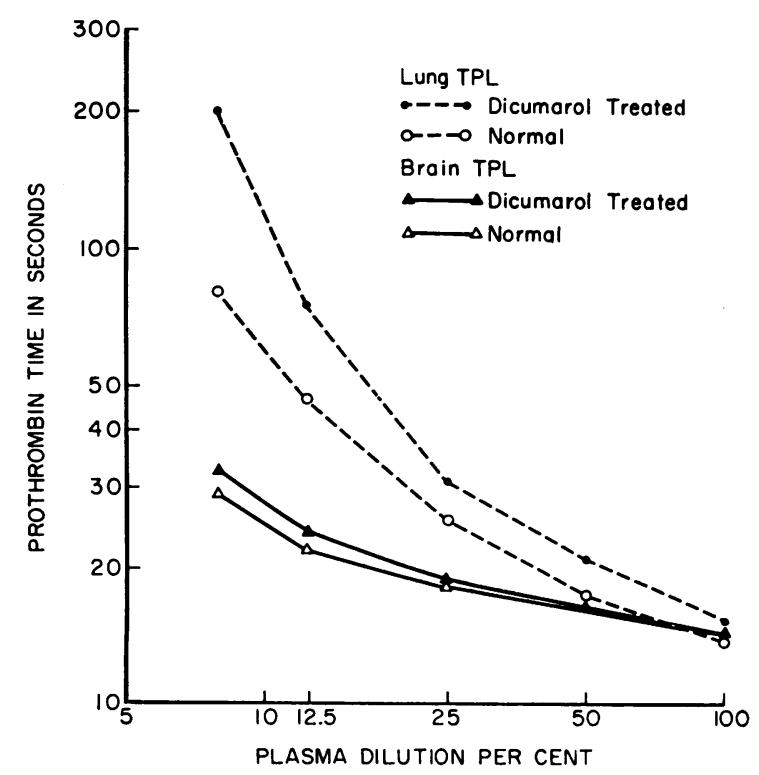

Fig. 3. Prothrombin times of Normal PLASMa Diluted WITH BASO 4 -ADSORBED PLASMA, USING BRAIN AND LUNG TPL From NORMaL aNd Dicumarol-treated RABBITS.

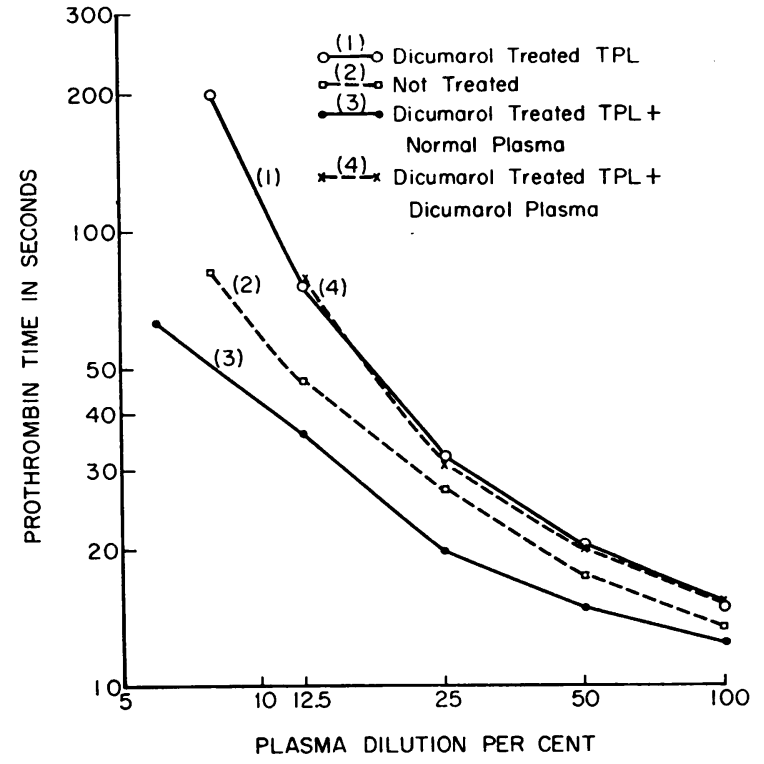

Fig. 4. Prothrombin times of Normal plasma diLuted With $\mathrm{BASO}_{4}$-Adsorbed PLASMa USING LUNG TPL 1) FROM RABBITS WHICH HAD RECEIVED Dicumarol aNd 2) FROM NORMAL RABBITS. Hemoglobin concentration of these extracts was $75 \mathrm{mg}$ per $100 \mathrm{ml}$. Curve 3 shows the result of adding to the "Dicumarol-treated" Tpl 0.0025 $\mathrm{ml}$ of normal rabbit plasma per $\mathrm{ml}$ of $\mathrm{Tpl}$ solution, which corresponds roughly to a hemoglobin contamination of $50 \mathrm{mg}$ per $100 \mathrm{ml}$. In curve 4 the same amount of plasma from a Dicumarol-treated rabbit was used.

factor VII activity is lower in brain than in lung Tpl.

The hemoglobin concentration in the brain $\mathrm{T} p \mathrm{pl}$ solution was $1.0 \mathrm{mg}$ per $100 \mathrm{ml}$, and in the lung $\mathrm{Tpl}, 80 \mathrm{mg}$ per $100 \mathrm{ml}$. It was estimated that a hemoglobin concentration of $50 \mathrm{mg}$ per $100 \mathrm{ml}$ corresponded to a plasma contamination of 0.0025 $\mathrm{ml}$ per $\mathrm{ml}$ of thromboplastin extract. Therefore, this amount of plasma was added to the Dicumarol-treated lung thromboplastin and the effect on its activity was observed (Figure 4 ). The addition of normal rabbit plasma resulted in a markedly enhanced activity, while the addition of an equivalent amount of plasma from a Dicumarol-treated animal had no effect.

It is concluded that contamination of $\mathrm{Tpl}$ by blood alters the activity considerably and that, because of its greater contamination, lung is more affected than brain Tpl. The hemoglobin concentrations in the commercial Tpl's used throughout this study were $2 \mathrm{mg}$ per $100 \mathrm{ml}$ for brain, and $37 \mathrm{mg}$ for lung $\mathrm{Tpl}$. 


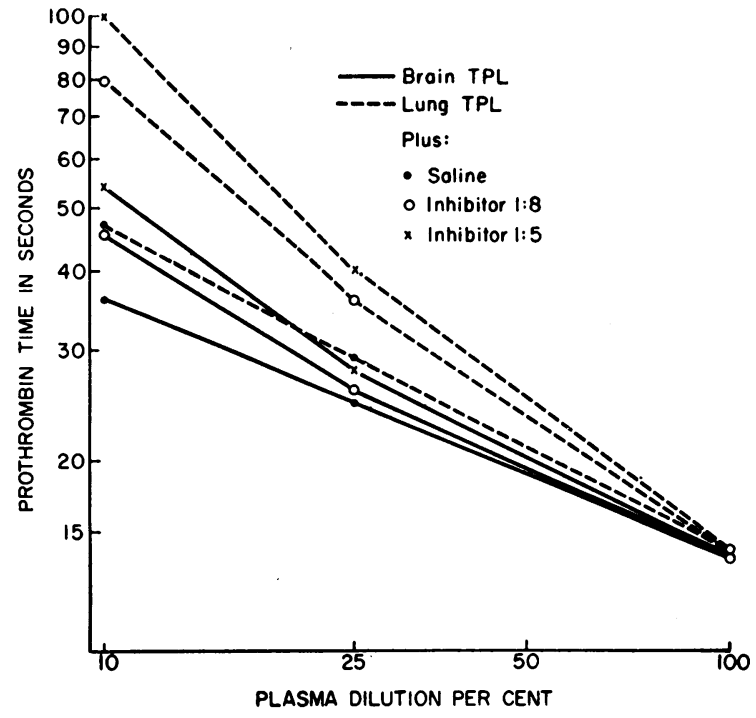

Fig. 5. EFFECT OF ADDING INHIBITOR TO NORMAL PLASMA DILUTED WITH SALINE: $0.2 \mathrm{ML}$ TPL $+0.1 \mathrm{ML}$ PLASMA +0.02 ML OF NORMAL SALINE OR INHIBITOR.

3. Effect of plasma prothrombin-conversion inhibitor (PPCI) on brain and lung Tpl. PPCI diluted $1: 5$ and $1: 8$ was added to plasma diluted with saline and prothrombin times were performed. The results show that the prolongation of the prothrombin times at increasing dilutions of

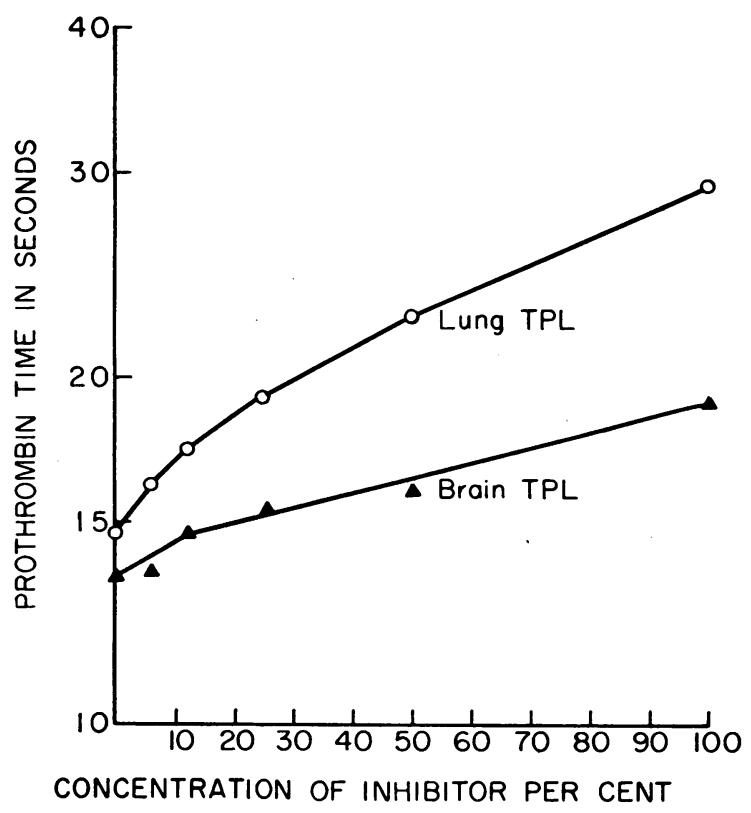

Fig. 6. EFFECT OF ADDING INHIBITOR TO NORMAL PLASMA: $0.2 \mathrm{ML}$ TPL $+\mathrm{CA}+0.1 \mathrm{ML}$ PLASMA $+0.02 \mathrm{ML}$ IN HIBITOR.

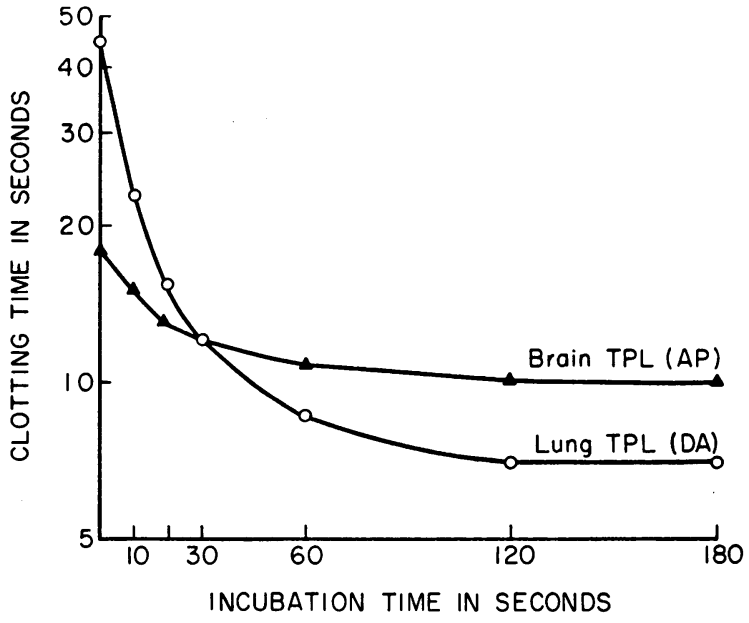

Fig. 7. Effect of PRe-Incubating TPL $+\mathrm{CA}_{\text {a }}$ With PLASMA ELUATE BEFORE ADDING TO BASO ${ }_{4}$-ADSORBED Plasma: $0.2 \mathrm{ML}$ TPL $+\mathrm{CA}+0.1$ ML PLASMa eluate (1:20) incubated for 2 MinUtes at $37^{\circ} \mathrm{C}$ and then $0.1 \mathrm{ML} \mathrm{BASO}_{4}$-ADSORBED PLASMA ADDED.

plasma was greater with lung than with brain $\mathrm{Tpl}$ (Figure 5).

Increasing concentrations of PPCI were added to normal plasma. The effects on the prothrombin time are shown in Figure 6. Increasing the concentration of inhibitor has a greater effect in prolonging the prothrombin time with lung than with brain Tpl.

The activity of the two types of $\mathrm{Tpl}$ was further studied in inhibitor-free systems. Tpl + calcium mixture was pre-incubated for varying periods of time with plasma eluate, then added to $\mathrm{BaSO}_{4}$ adsorbed plasma and the clotting time recorded (Figure 7). When plasma eluate diluted 1:20 was added to $\mathrm{Tpl}+\mathrm{Ca}$ and the mixture was added immediately to adsorbed plasma without preincubation, lung Tpl gave a clotting time of 45 seconds, while brain gave 18 seconds. However, with pre-incubation, the clotting time obtained with lung $\mathrm{Tpl}$ sharply decreased. After 2 minutes of pre-incubation, it was shortened to 7 seconds, compared with 10 seconds for brain $\mathrm{Tpl}$. When eluate dilutions of $1: 40$ were used, pre-incubation for 2 minutes with lung $\mathrm{Tpl}$ shortened the clotting time from 155 to 12 seconds, whereas with brain $\mathrm{Tpl}$ it was only shortened from 34 to 20 seconds. Thus, in the absence of inhibitor, lung Tpl appeared to be more active than brain $\mathrm{Tpl}$.

The effect of inhibitor on the prothrombin conversion system was then studied. Plasma eluate 


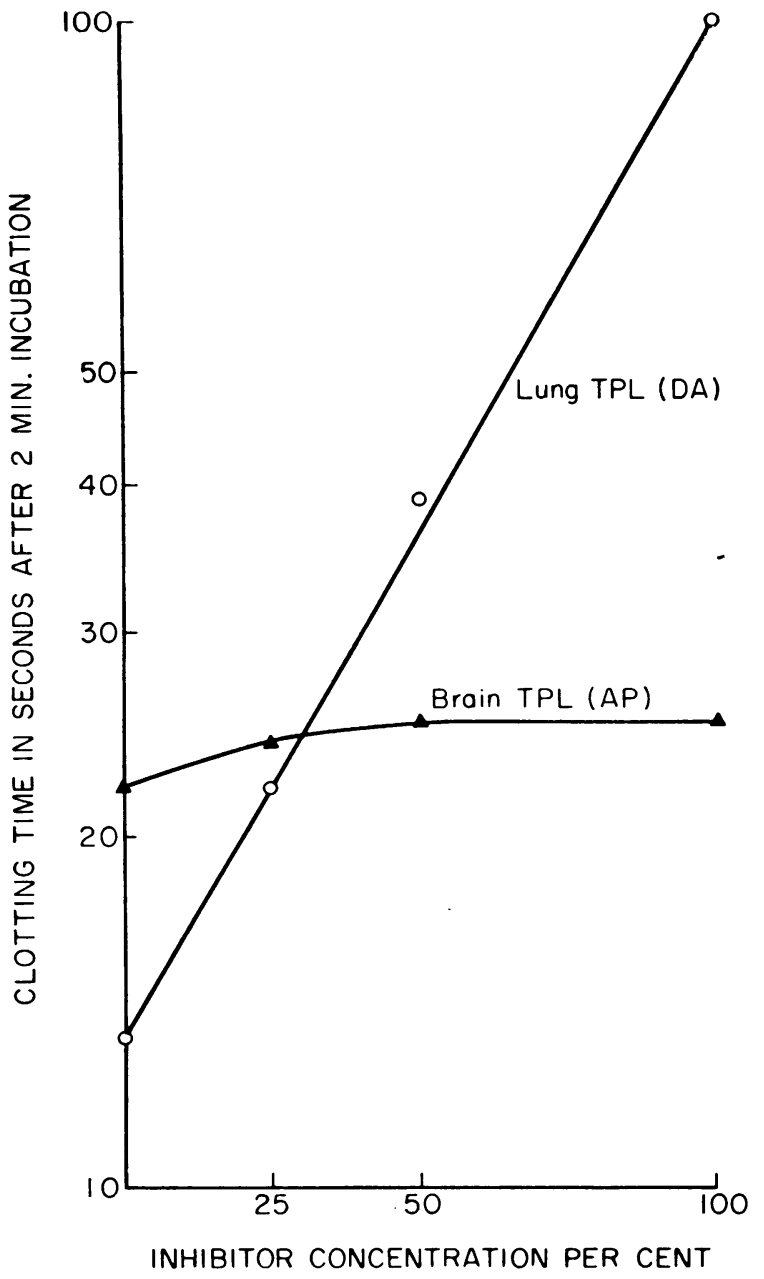

Fig. 8. EFFECT OF ADdiNg INHIBITOR DURING the PREincubation ( 2 minutes) OF TPL With PLASMa eluate: $0.2 \mathrm{ML}$ Tpl + Ca +0.1 ml plasma eluate $(1: 40)+0.02$ ML INHIBITOR DILUTED IN SALINE INCUBATED 2 MINUTES at $37^{\circ} \mathrm{C}$ and then 0.1 ML BaSO $4^{-A D S O R B E D}$ PLASMa ADDED.

and $\mathrm{Tpl}+\mathrm{Ca}$ were pre-incubated in the presence of increasing amounts of inhibitor for 2 minutes, at which time $\mathrm{BaSO}_{4}$-adsorbed plasma was added. A dilution of plasma eluate of $1: 40$ was used in this experiment. Figure 8 shows the marked effect of the inhibitor on lung $\mathrm{Tpl}$ and the negligible effect on brain Tpl.

Studies were also performed with varying concentrations of eluate and inhibitor (Figure 9). Pre-incubation of $\mathrm{Tpl}+\mathrm{Ca}+$ eluate was again carried out for 2 minutes in the presence of inhibitor. The results show that with no inhibitor, lung $\mathrm{Tpl}$ was more active (i.e., gave shorter prothrom- lin times) than did brain $T_{1}$ l at all concentrations of plasma eluate. When inhibitor was added, there was virtually no effect on the curves obtained with brain $\mathrm{Tpl}$, while the curves obtained with lung $\mathrm{Tpl}$ became widely divergent:

Further studies were then carried out to determine the reason for the greater activity of lung Tpl when pre-incubated with plasma eluate. During this pre-incubation, activation of at least two systems, factor VII and prothrombin (13-16), is known to occur.

To determine the effects of pre-incubation on the factor VII system, the $\mathrm{Tpl}+\mathrm{Ca}$ mixtures were pre-incubated with a serum eluate for varying periods of time and then added to a mixture containing $\mathrm{BaSO}_{4}$-adsorbed plasma and purified

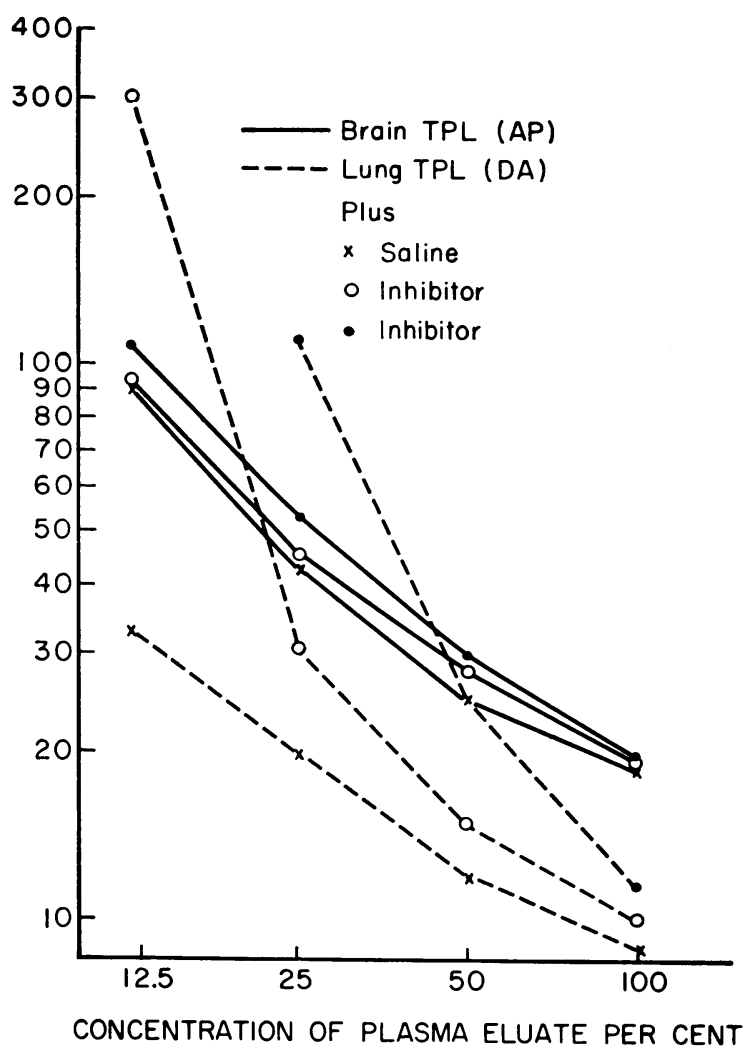

Fig. 9. EFFECT OF ADDING INHIBITOR DURING PRE-INCUbation ( 2 minutes) of Tpl with plasma eluate: 0.2 mL TPL $+\mathrm{CA}+0.1$ mL Plasma eluate of varying CONCENTRATION +0.02 ML NORMAL SALINE OR INHIBITOR INCubated 2 minutes at $37^{\circ} \mathrm{C}$ and then 0.1 mL BaSO $4^{-}$ ADSORBED PLASMA ADDED. A 1:20 eluate dilution is represented as 100 per cent. Inhibitor $1: 20$ is represented by solid circles. Inhibitor $1: 40$ is represented by open circles. 


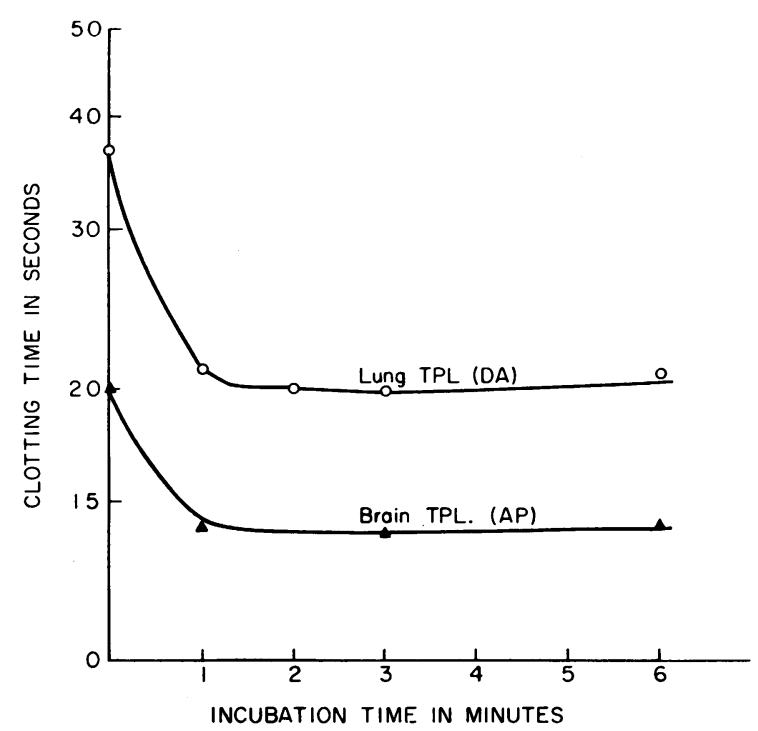

Fig. 10. Effect of pre-incubating Tpl with serum eluate: $0.2 \mathrm{ML}$ Tpl $+\mathrm{CA}_{\mathrm{A}}+0.1 \mathrm{ML}$ Serum eluate $(1: 40)$ INCUBATED FOR VARYING TIME AT $37^{\circ} \mathrm{C}$ FOLLOWED BY THE ADDITION OF $0.1 \mathrm{ML} \mathrm{BASO}_{4}$-ADSORBED PLASMA + $0.1 \mathrm{ML}$ PURIFIED PROTHROMBIN (12.5 U ADDED).

prothrombin. This is, in essence, a factor VII generation test and, as may be seen in Figure 10, the rate of change of activity is the same for both types of $\mathrm{Tpl}$, and the brain $\mathrm{Tpl}$ develops greater maximal activity.

When, however, the $\mathrm{Tpl}+\mathrm{Ca}$ mixtures are preincubated with purified prothrombin and then added to a mixture of $\mathrm{BaSO}_{4}$-adsorbed plasma and serum eluate (Figure 11), the lung shows a marked increase in activity while the activity of brain $\mathrm{Tpl}$ is virtually unchanged.

The increase in activity of lung $\mathrm{Tpl}$ during preincubation with prothrombin probably represents actual thrombin formation. When $\mathrm{Tpl}+\mathrm{Ca}$ was pre-incubated with $25 \mathrm{U}$ of prothrombin for 3 minutes and then added to a $\mathrm{BaSO}_{4}$-adsorbed fibrinogen solution ( 0.4 per cent), a clot was obtained in 50 seconds with lung $\mathrm{Tpl}$, while with brain $\mathrm{Tpl}$ the clotting time was 12 minutes.

The possibility of contamination of lung $\mathrm{T} p \mathrm{l}$ with factor $\mathrm{V}$ was studied. The markedly greater thrombin-forming capacity of lung $\mathrm{Tpl}$ in the presence of purified prothrombin indicated that the lung $\mathrm{Tpl}$ probably contained a significant amount of factor $\mathrm{V}$ activity. To compare this activity with that in brain $\mathrm{T} p \mathrm{pl}$, prothrombin times were performed on plasma whose factor $\mathrm{V}$ concentration

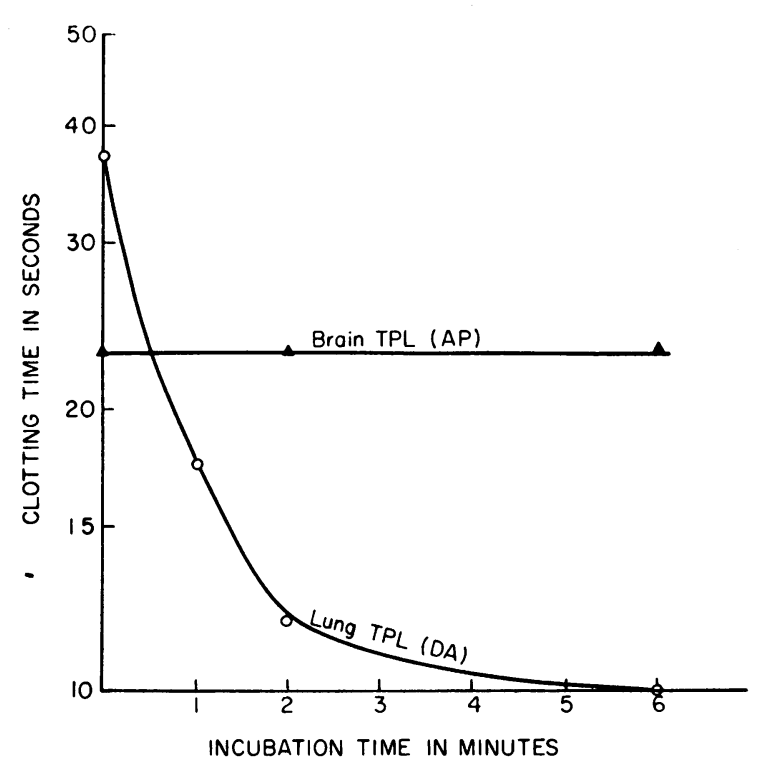

Fig. 11. Effect of PRE-incubating TPL with purified PROTHROMBIN : $0.2 \mathrm{ML}$ TPL $+\mathrm{CA}+0.1 \mathrm{ML}$ PROTHROMBIN $(12.5 \mathrm{U})$ inCUBATED FOR VARYiNg TIME AT $37^{\circ} \mathrm{C}$, FOLLOWED BY THE ADDITION OF 0.1 ML B $\Lambda$ SO 4 -ADSORBED PLASMA +0.1 ML SERUM ELUATE $(1: 40)$.

had been reduced by dilution with aged, normal plasma (Figure 12). With lung $\mathrm{Tpl}$ the curve was flatter, and at very low concentrations of factor $\mathrm{V}$ the prothrombin times were shorter than with brain Tpl. Freezing and thawing can reduce factor $\mathrm{V}$ activity of plasma. The reduction of $\mathrm{Tpl}$ activity of lung preparations after freezing may be a result of the destruction of contaminant factor V.

The possible mechanism of action of the inhibitor was next studied (Table I). When lung $\mathrm{Tpl}$ $+\mathrm{Ca}+$ serum eluate, $1: 40,+$ prothrombin were

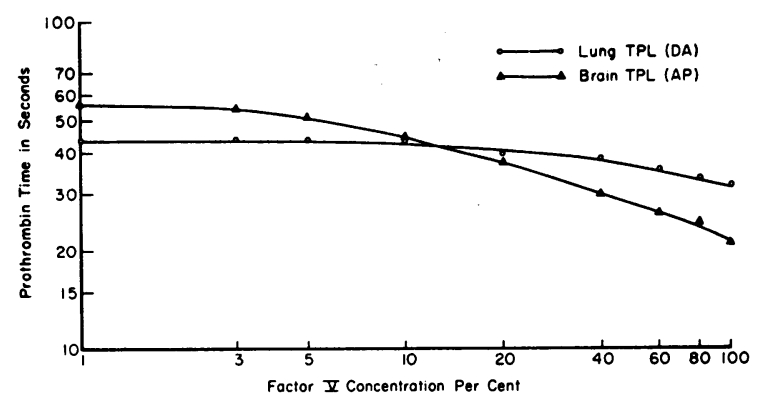

Fig. 12. EFFeCt of FACTOR V DILUtion on PRothromBIN TIMEs. Normal plasma was diluted with saline (1 to 100 per cent) and $0.1 \mathrm{ml}$ was added to $0.9 \mathrm{ml}$ of aged plasma. Prothrombin times were done on $0.1 \mathrm{ml}$ of this mixture. 
TABLE I

Action of inhibitors *

\begin{tabular}{|c|c|c|c|c|c|}
\hline \multirow{2}{*}{$\begin{array}{l}\text { Experiment } \\
\text { no. }\end{array}$} & \multicolumn{4}{|c|}{ Time added (min) } & \multirow{2}{*}{$\begin{array}{l}\text { Clotting } \\
\text { time } \\
\text { (sec) }\end{array}$} \\
\hline & 0 & 2 & 4 & 6 & \\
\hline $\begin{array}{l}1 \\
2 \\
3 \\
4 \\
5 \\
6 \\
7\end{array}$ & Bat + Proth. $\ddagger$ & $\begin{array}{l}\text { Ba + Proth. } \\
\text { Proth. } \\
\text { Proth. + In. } \$ \\
\text { Proth. } \\
\text { Proth. }\end{array}$ & $\begin{array}{l}\mathrm{Ba}+\text { Proth. } \\
\mathrm{Ba} \\
\text { In. }\end{array}$ & $\begin{array}{l}\mathrm{Ba} \\
\mathrm{Ba}\end{array}$ & $\begin{array}{l}55 \\
21 \\
24 \\
10 \\
62 \\
12 \\
13\end{array}$ \\
\hline
\end{tabular}

* Two-tenths $\mathrm{ml}$ lung $\mathrm{Tpl}(\mathrm{DA})+\mathrm{Ca}$ were added to $0.1 \mathrm{ml}$ of serum eluate, $1: 40$, at zero time. The substances indicated were added at $0,2,4$ and 6 minutes. Clotting times were obtained after the addition of $\mathrm{BaSO}_{4}$-adsorbed plasma. $\dagger \mathrm{BaSO}_{4}$-adsorbed plasma, $0.1 \mathrm{ml}$. $\ddagger$ Purified prothrombin $(12.5 \mathrm{U})$.

$\S$ Inhibitor, $0.02 \mathrm{ml}$.

mixed with $\mathrm{BaSO}_{4}$ plasma without any pre-incubation, a clotting time of 55 seconds was obtained. If the $\mathrm{Tpl}+\mathrm{Ca}$ was pre-incubated with serum eluate before adding the adsorbed plasma and prothrombin (thereby activating factor VII), a maximal shortening of the clotting time (21 seconds) was achieved after 2 minutes of pre-incubation (Experiments 1,2 and 3).

Using this procedure, the experiment was conducted as follows: $\mathrm{Tpl}+\mathrm{Ca}+$ serum eluate were incubated for 2 minutes, then prothrombin was added and after 2 minutes more the adsorbed plasma was added; clotting occurred at $10 \mathrm{sec}-$ onds. If, in this sequence, inhibitor was added at the same time as the prothrombin, clotting occurred at 62 seconds.

If the addition of inhibitor was delayed until thrombin had formed, there was no inhibition. Thus, if prothrombin was added at 2 minutes, inhibitor at 4 minutes, and adsorbed plasma at 6 minutes, clotting occurred at 12 seconds. It would seem that the inhibitor acts by interfering with the conversion of prothrombin to thrombin and is effective even after factor VII has been activated.

4. Studies of lung and brain Tpl on patients receiving coumarin drugs. Prothrombin times were performed on an unselected group of patients who were receiving Coumadin, ${ }^{2}$ using lung and brain Tpl. The prothrombin activity was calculated as percentage of normal plasmas diluted with adsorbed plasma and with saline (Figure 13). In all cases the prothrombin times obtained with lung Tpl were longer than those obtained with brain

\footnotetext{
2 Warfarin sodium.
}

Tp1. When prothrombin activity was calculated from the saline dilution curves, the values were always lower for lung than for brain Tpl. However, on the adsorbed plasma dilution curve, the value for lung $\mathrm{Tpl}$ was higher. Similar results were obtained on a patient who was followed throughout a course of therapy with Coumadin (Figure 14).

The choice of diluent markedly affected the calculation of percentage activity when brain $\mathrm{Tpl}$ was used; with saline, the values were considerably higher than with adsorbed plasma. With lung Tpl, the calculated activity was essentially the same for both diluents.

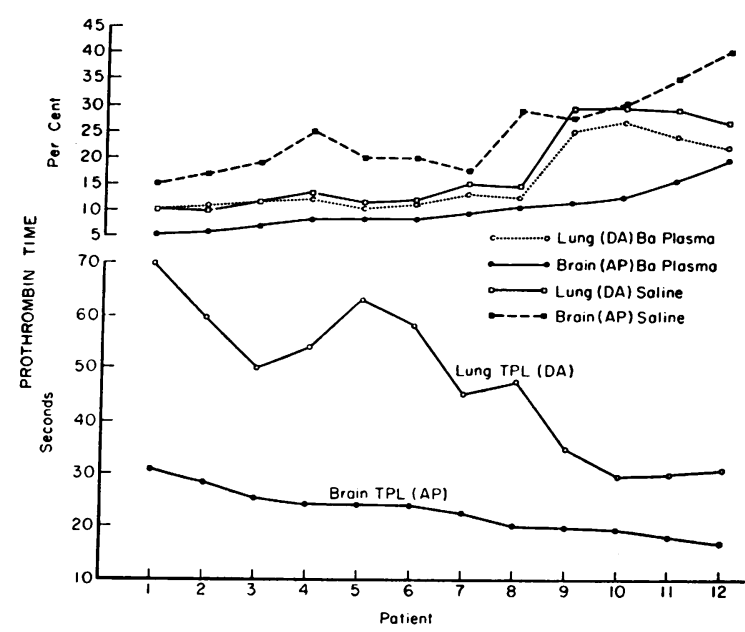

Fig. 13. Prothrombin Determinations on 12 PATIENTS RECEIVING CoUMADIN, USING LUNG AND BRAIN TPL. The results are expressed in seconds and percentage of normal activity, using reference dilution curves obtained with $\mathrm{BaSO}_{4}$-adsorbed plasma or saline. 


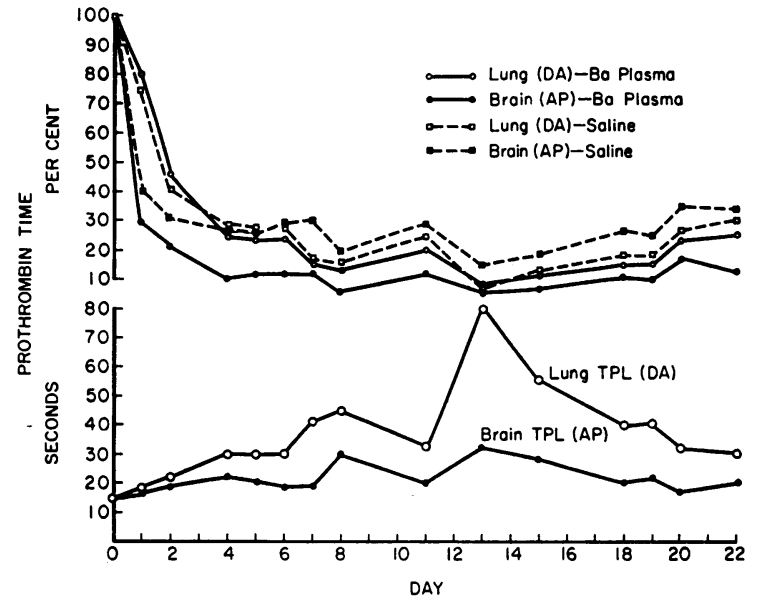

Fig. 14. Prothrombin determinations on a Single PATIENT Who Received Coumadin, using Lung AND BRAIN TPL. Calculation of percentage was obtained from both saline and $\mathrm{BaSO}_{4}$-adsorbed plasma dilution curves.

\section{DISCUSSION}

When different tissue Tpl's are used to perform prothrombin times on the plasma of a patient receiving coumarin derivatives, widely varying results may be obtained $(1,2,6,17-21)$. In particular, it has been noted that lung Tpl's give longer prothrombin times than do brain Tpl's. Verstraete and co-workers also showed that the disproportionately long prothrombin times obtained with lung $\mathrm{Tpl}$ and plasma diluted with $\mathrm{BaSO}_{4}$-adsorbed plasma was due to a dilution not of prothrombin, but of factor VII (1). They concluded that this difference might represent a greater factor VII-like activity of brain extracts, and they suggested therefore that lung $\mathrm{Tpl}$ might be a more sensitive indicator of factor VII depletion. Other authors have also stressed the possibility of "activators" in tissue Tpl $(19,20)$. Since a reduction in factor VII appears to be a major effect of coumarin drugs $(22,23)$, the employment of a tissue $\mathrm{Tpl}$ sensitive to changes in its activity is obviously important for controlling coumarin therapy. It is for such reasons that Russell's viper venom, which apparently contains factor VII activity, is not recommended $(3,4)$.

However, the longer prothrombin times obtained with lung extracts do not necessarily mean that brain $\mathrm{Tpl}$ contains more factor VII-like activity. The previous work of Conley and associates (6) suggested that lung $\mathrm{Tpl}$ might be more sensitive to the effect of an inhibitor in
$\mathrm{BaSO}_{4}$-adsorbed plasma. In view of the findings of Verstraete and co-workers $(1,2)$ this inhibitor might involve the factor VII system. Such plasma inhibitors of the prothrombin conversion system have been described. Wagner, Brannan and Brinkhous (24) described an antagonist of factor VII present in the fraction of canine plasma which is precipitated by ammonium sulfate between 70 and 80 per cent saturation. Schaefer, Therriault and Jensen (25) described an inhibitor in rabbit serum which precipitated between 50 and 80 per cent saturation and which inhibited the interaction of prothrombin-converting factor (presumably factor VII) and prothrombin. In addition, a lipidextractable inhibitor in plasma with the properties of an antithromboplastin has been described (26), which may act by inhibiting the activation of factor VII (25). Other Tpl inhibitors have been reported by Overman (27) and by Lanchantin and Ware (28).

Our studies indicate that an inhibitor, precipitated by ammonium sulfate between 50 and 80 per cent saturation, is present in human plasma. This inhibitor is more active when lung extract is used as a source of tissue $\mathrm{T}$ pl than when brain extract is used. The presence of such an inhibitor would explain why lung $\mathrm{T} p \mathrm{pl}$ gives longer prothrombin times at increasing dilutions of plasma in $\mathrm{BaSO}_{4}$-adsorbed plasma than does brain $\mathrm{Tpl}$. It would also explain the shortening of the prothrombin time observed for lung $\mathrm{Tpl}$ when saline instead of $\mathrm{BaSO}_{4}$-adsorbed plasma was used as a diluent. Therefore, the shorter prothrombin times obtained with brain $\mathrm{T} p 1$ on the plasma of anticoagulated patients need not mean that brain extract contains more factor VII activity, nor is it necessarily a less sensitive $\mathrm{Tpl}$.

The importance of expressing prothrombin activities as percentage of normal rather than as absolute prothrombin times has been stressed (17). In this respect, the choice of diluent used in obtaining a normal curve is important. The ideal diluent would be human plasma which has been depleted of factors reduced by coumarin derivatives. Conley and associates (6) showed that $\mathrm{BaSO}_{4}$-adsorbed plasma best approximates this. Our studies have shown that, when this diluent is used, brain $\mathrm{Tpl}$, although giving a shorter prothrombin time, actually reveals a lower percentage of activity than does lung Tpl. 


\section{SUMMARY}

The differences in activity between lung and brain thromboplastin ( $\mathrm{Tpl}$ ) have been studied-in particular, the greater prolongation of the prothrombin times obtained with lung Tpl at decreasing factor VII concentration. It was found that lung extract was actually more active when the prothrombin conversion system was studied in the absence of plasma inhibitors. In the presence of purified prothrombin, lung $\mathrm{Tpl}$ produced a greater coagulant effect than did brain thromboplastin.

The values obtained with lung $\mathrm{Tpl}$ are evidently subject to two uncertain variables: 1) the amount of blood remaining in the tissue extract, and 2) the susceptibility of lung $\mathrm{Tpl}$ to the effect of an inhibitor present in normal plasma. Thus, one variable tends to speed up the prothrombin time; the other tends to slow it down. The results obtained with lung Tpl could vary with factors other than the "prothrombin complex" in the plasma of the patient.

Brain $\mathrm{Tpl}$ is not subject to these variables. It contains insignificant amounts of blood and it is not affected by the inhibitor.

The practice of mixing lung and brain $\mathrm{Tpl}$ in unspecified proportions, as recommended by the USP (16th ed.), would seem to compound the variables and the problems of controlling anticoagulant therapy.

\section{REFERENCES}

1. Verstraete, M., Clark, P. A., and Wright, I. S. Use of different tissue thromboplastins in the control of anticoagulant therapy. Circulation 1957, 16, 213.

2. Verstraete, M., Clark, P. A., and Wright, I. S. Evaluation of prothrombin times performed with different thromboplastins. Acta med. scand. 1959, $163,105$.

3. Rapaport, S. I., Aas, K., and Owren, P. The clotting action of Russell viper venom. Blood 1954, 9, 1185.

4. Jenkins, J. S. The thromboplastic activity of Russell's viper venom and its relationship to factor VII. J. clin. Path. 1954, 7, 287.

5. Mann, F. D., and Hurn, M. S. The complex mechanisms of the Quick prothrombin test and the effect of Dicumarol. Amer. J. clin. Path. 1950, 20, 225.

6. Conley, C. L., Morse, W. I., II, and Stewart, E. E. Thromboplastic factors in the estimation of prothrombin concentration. Amer. J. med. Sci. 1948, 215,158 .
7. Tocantins, L. M. Estimation of prothrombin by the one-stage method of Quick in The Coagulation of Blood, I. M. Tocantins, Ed. New York, Grune \& Stratton, 1955 , p. 98.

8. Johnson, J. F., and Seegers, W. H. Estimation of Ac-globulin activity by the two-stage method in The Coagulation of Blood, L. M. Tocantins, Ed. New York, Grune \& Stratton, 1955, p. 131.

9. Bose, A. N. On the mode of action of dicoumarin. Ann. Biochem. 1945, 5, 105.

10. Stefanini, M., and Blanchaer, M. C. Action of 3,3methylenebis (4-hydroxycoumarin) (Dicumarol) on thromboplastic activity of rabbit brain. Proc. Soc. exp. Biol. (N. Y.) 1947, 64, 47.

11. Munro, F. L., and Lupton, A. M. The influence of Dicumarol treatment of rabbits, rats and dogs on the thromboplastic activity of their brain suspensions. Arch. Biochem. 1947, 15, 245.

12. Rosti, P. Action of Dicumarol on the thromboplastic activity of rabbit brain. Boll. Ist. Sier. Mil. 1949, 27, 122.

13. Owren, P. A., and Bjerkelund, C. A new, previously unknown clotting factor. Scand. J. clin. Lab. Invest. $1949,1,162$.

14. Owren, P. A. La proconvertine. Rev. Hémat. 1952, 7, 147.

15. Mann, F. D., and Hurn, M. Co-thromboplastin, a probable factor in coagulation of blood. Amer. J. Physiol. 1951, 164, 105.

16. Landwehr, G., and Alexander, B. Interaction of spca with platelets or thromboplastin in prothrombin conversion. Fed. Proc. 1951, 10, 212.

17. Hurn, M., Barker, N. W., and Magath, T. B. The determination of prothrombin time following the administration of Dicumarol, 3,3'-methylenebis (4hydroxycoumarin), with special reference to thromboplastin. J. Lab. clin. Med. 1945, 30, 432.

18. Bassen, F. A. The variability of prothrombin time determinations with "standardized thromboplastin" preparations. J. Mt Sinai Hosp. 1955, 22, 112.

19. Koppel, J. L., Arscott, P. M., Friedman, L. H., and Olwin, J. H. Differences in tissue thromboplastins and their influence on the control of anticoagulant therapy. Surgery 1958, 43, 94.

20. Caldwell, M. J., and Priest, E. M. A different concept of prothrombin time control for anticoagulative therapy. Amer. Heart J. 1958, 56, 737.

21. Shapiro, S. Comparison of thromboplastic activity of lyophilized preparations of thromboplastin. Amer. J. clin. Path. 1960, 33, 220.

22. Mann, F. D., Barker, N. W., and Hurn, M. The effect of Dicumarol on co-thromboplastin, a factor in blood concerned with the conversion of prothrombin to thrombin. Blood 1951, 6, 838.

23. Hunter, R. B., and Tudhope, G. R. Mode of action of Tromexan. Lancet 1953, 1, 821.

24. Wagner, R. H., Brannan, W. M., Jr., and Brinkhous, K. M. Antiaccelerator (anticonvertin) activity of 
canine plasma and serum. Proc. Soc. exp. Biol. (N. Y.) 1955, 89, 266.

25. Schaefer, E. H., Jr., Therriault, D. G., and Jensen, H. Studies on a prothrombin conversion inhibitor fraction from rabbit serum. J. appl. Physiol. 1955, 8, 300.

26. Tocantins, L. M., and Carroll, R. T. Separation and assay of a lipid antithromboplastin from human brain, blood plasma and plasma fractions in Trans. Second Conference on Blood Clotting and Allied
Problems, J. E. Flynn, Ed. New York, Josiah Macy, Jr. Foundation, 1949, p. 11.

27. Overman, R. S. The chemical purification and mode of action of a thromboplastic inhibitor in Trans. Second Conference on Blood Clotting and Allied Problems, J. E. Flynn, Ed. New York, Josiah Macy, Jr. Foundation, 1949, p. 29.

28. Lanchantin, G. F., and Ware, A. G. Identification of a thromboplastin inhibitor in serum and in plasma. J. clin. Invest. 1953, 32, 381. 